bioRxiv preprint doi: https://doi org/10.1101/2022 $02.22 .481552 \cdot$ this version posted February 25,2022 . The copyright holder for this

\title{
Plastomes of Garcinia mangostana L. and comparative analysis with other Garcinia species
}

Ching-Ching Wee ${ }^{1,2}$, Nor Azlan Nor Muhammad ${ }^{1}$, Vijay Kumar Subbiah ${ }^{2}$, Masanori Arita ${ }^{3}$, Yasukazu Nakamura ${ }^{3}$, Hoe-Han Goh $^{1 *}$

${ }^{1}$ Institute of Systems Biology, Universiti Kebangsaan Malaysia, 43600 Bangi, Selangor, Malaysia.

${ }^{2}$ Biotechnology Research Institute, Universiti Malaysia Sabah, 88400 Kota Kinabalu, Sabah, Malaysia.

${ }^{3}$ National Institute of Genetics, Mishima, 411-8540 Shizuoka, Japan.

\section{*Correspondence:}

E-mail: gohhh@ukm.edu.my

Short Title: Plastomes of Garcinia mangostana 


\begin{abstract}
The two varieties of mangosteen (Garcinia mangostana L.) cultivated in Malaysia are known as Manggis and Mesta. The latter is preferred for its flavor, texture, and seedlessness. Here, we report a complete plastome $(156,580 \mathrm{bp})$ of the Mesta variety which was obtained through a hybrid assembly approach using PacBio and Illumina sequencing reads. It encompasses a large single-copy (LSC) region (85,383 bp) and a small single-copy (SSC) region (17,137 bp) that are separated by 27,230 bp of inverted repeat (IR) regions at both ends. The plastome comprises 128 genes, namely 83 protein-coding genes, 37 tRNA genes, and 8 rRNA genes. The plastome of the Manggis variety (156,582 bp) obtained from reference-guided assembly of Illumina reads was found to be nearly identical to Mesta except for two indels and the presence of a single nucleotide polymorphism (SNP). Comparative analyses with other publicly available Garcinia plastomes, including G. anomala, G. gummi-gutta, G. mangostana var. Thailand, G. oblongifolia, G. paucinervis, and G. pedunculata found that the gene content, gene order, and gene orientation were highly conserved among the Garcinia species. Phylogenomic analysis divided the six Garcinia plastomes into three groups with the Mesta and Manggis varieties clustered closer to G. anomala, G. gummi-gutta, and G. oblongifolia, while the Thailand variety clustered with G. pedunculata in another group. These findings serve as future references for the identification of species or varieties and facilitate phylogenomic analysis of lineages from the Garcinia genus to better understand their evolutionary history.
\end{abstract}

Keywords: Garcinia; Manggis; Mesta; phylogenomic analysis; plastome 


\section{Introduction}

Mangosteen (Garcinia mangostana L.) is well-known as the 'queen of fruits' and is mainly found in Southeast Asia, particularly in Malaysia, Indonesia, and Thailand ${ }^{1}$. It is priced for its unique taste and valuable natural compounds. Xanthones, which are abundantly found in the ripe fruit pericarp, have been shown to possess antioxidant, anti-cancer, anti-inflammatory, anti-bacterial, and anti-viral properties ${ }^{2}$.

The geographical origin of G. mangostana is still under debate. Unlike other flowering plants, G. mangostana reproduces apomictically by adventitious embryony in the mother plant without fertilization ${ }^{3}$ and produces Garcinia-type recalcitrant seeds without embryo ${ }^{4}$. Morphological and phylogenetic analyses have been performed to examine the parental origin of G. mangostana and its relationship with other Garcinia species based on internal transcribed spacer $(I T S)^{5-7}$, granule-bound starch synthase $(G B S S I)^{7}, \operatorname{trnS}$-trnG, and combination of trnS$\operatorname{trn} G$ with $\operatorname{trn} D-\operatorname{trn} T^{8}$. They showed that G. mangostana was closely related to G. malaccensis and as such, were postulated to have been derived from the hybridization of G. hombroniana and $G$. malaccensis ${ }^{9}$. However, as there was only one mangosteen sample (G. mangostana TH3) that showed heterozygosity in the ITS gene, Nazre proposed G. mangostana and G. malaccensis to be grouped as one species but different varieties ${ }^{10}$. Mangosteen was suggested to have originated either from the hybrid of different varieties of G. malaccensis or the end product of agricultural selective breeding retaining only superior female plants of $G$. malaccensis ${ }^{10}$.

Nonetheless, several reports showed that molecular markers from the nuclear genome could not provide sufficient information for phylogeny demarcation ${ }^{11}$. This is likely due to recombination events in the plant nuclear genome during reproduction ${ }^{12}$. In contrast, the majority of the plastome is inherited maternally. Hence, plastome with a slower rate of evolution provides a better resolution in examining species phylogenetic relationships, adaptive evolution, and divergence dating ${ }^{13,14}$. Recently, with the advancement of nextgeneration sequencing and long-read sequencing technology, complete plastomes can be obtained easily at low costs. A complete plastome of G. mangostana of an unspecified variety that originated from Thailand was first reported in 2017 with the accession number KX822787 15 (herein, denoted as the Thailand variety) and was shown to be closely related to G. pedunculata ${ }^{15}$. In Malaysia, two varieties of G. mangostana (Manggis and Mesta) were sequenced and deposited to GenBank ${ }^{16-18}$. However, a complete analysis of the plastomes from these two varieties is yet to be reported. 
In this study, we assembled and analyzed the complete mangosteen plastomes of Manggis and Mesta. Furthermore, we performed a comprehensive comparison of all available Garcinia plastomes from GenBank and provided an update to a previous comparative analysis $^{19}$. The current comparative study elucidates the structural differences in plastomes for evolutionary inference of the Garcinia genus.

\section{Results}

\section{Characterization of the Mesta plastome}

De novo assembly of PacBio subreads data using CANU assembler and error-correction with Illumina data using Pilon program produced a total of 7,616 contigs with an N50 genome length of 10,212 bp (Table S1). There was one contig (tig00037541_pilon) with the size of $\sim 165 \mathrm{~kb}$ that showed high similarity with the reference plastome in BLAT analysis. It was a circular contig as indicated by the dot plot analysis using $\operatorname{Gepard}^{20}$ (Figure S1). One of the identical overlapping ends $(\sim 9.3 \mathrm{~kb})$ was trimmed and 18 bases were manually added based on Illumina read correction to obtain the final Mesta plastome size of 156,580 bp. The average coverage of Mesta plastome with PacBio subreads and Illumina clean reads was 265X and 3,751X, respectively (Figure $\mathrm{S} 2 \&$ Table S2).

The Mesta plastome constituted a typical conserved quadripartite structure with two inverted repeat (IR) regions (each 27,030 bp) separating the large single-copy (LSC) region $(85,383 \mathrm{bp})$ from the small single-copy (SSC) region (17,137 bp) (Figure 1). The average GC content of the plastome was $36.2 \%$ while, the GC content in LSC, SSC, and IR regions was $33.6 \%, 30.2 \%$, and $42.2 \%$, respectively. A total of 128 genes were identified, including 77 unique protein-coding genes with 6 duplicated genes in IR; 30 unique tRNAs ( 7 duplicated genes in IR), and 4 rRNAs (4 duplicated genes in IR) (Table $1 \&$ Table 2). 


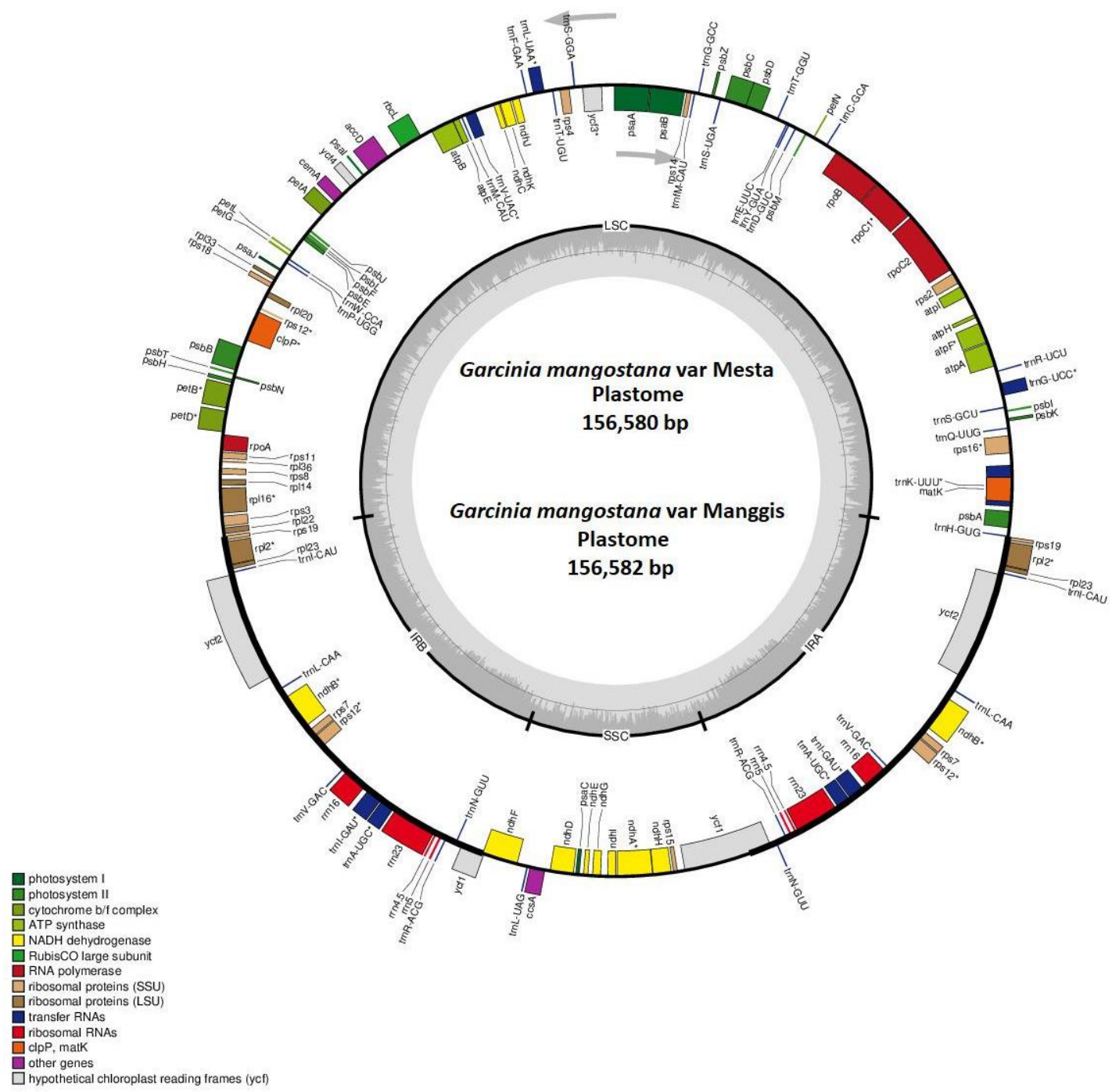

Figure 1. The circular plastome of G. mangostana variety Mesta and Manggis. Genes inside the circle are transcribed clockwise while genes outside the circle are transcribed anticlockwise as indicated by the gray arrows. The gray bars inside the circle represent the GC content of the sequence. Asterisks $(*)$ indicate genes containing intron(s).

\section{Manggis plastome assembly}

The Manggis Illumina clean reads had a higher mapping rate to the Mesta plastome than the Thailand variety (Figure S3 \& Table S3). Hence, the Mesta plastome was used for a referenceguided genome assembly of the Manggis plastome. The complete plastome of Manggis had a genome size of 156,582 bp (Table 1) after manual curation with the same genome features as observed in the Mesta plastome (Figure 1) except for one single nucleotide polymorphism (SNP) and two indels (Figure S4 \& Table S4). The average coverage of the Manggis plastome with the Illumina short reads was 2,636X (Table S3). 
Table 1. Summary statistics of plastomes from different Garcinia species.

\begin{tabular}{|c|c|c|c|c|c|c|c|c|c|c|c|c|c|}
\hline \multirow{2}{*}{ Species } & & \multirow{2}{*}{$\begin{array}{l}\text { Plastome } \\
\text { size (bp) }\end{array}$} & \multicolumn{3}{|c|}{ Size (bp) } & \multicolumn{4}{|c|}{ Number of genes* } & \multicolumn{4}{|c|}{ GC content $(\%)$} \\
\hline & & & LSC & SSC & IR & All & $\begin{array}{c}\text { Protein- } \\
\text { coding }\end{array}$ & rRNA & tRNA & All & LSC & SSC & IR \\
\hline G. gummi-gutta & & 156,202 & 84,996 & 17,088 & 27,059 & 127 (110) & $83(77)$ & $8(4)$ & $36(29)$ & 36.2 & 33.5 & 30.3 & 42.1 \\
\hline \multirow[t]{2}{*}{ G. mangostana } & Manggis & 156,582 & 85,385 & 17,137 & 27,030 & $128(111)$ & $83(77)$ & $8(4)$ & $37(30)$ & 36.2 & 33.6 & 30.2 & 42.2 \\
\hline & Thailand & 158,179 & 86,458 & 17,703 & 27,009 & $128(111)$ & $83(77)$ & $8(4)$ & $37(30)$ & 36.1 & 33.5 & 30.1 & 42.2 \\
\hline G. oblongifolia & & 156,577 & 85,393 & 17,064 & 27,060 & $128(111)$ & $83(77)$ & $8(4)$ & $37(30)$ & 36.2 & 33.6 & 30.3 & 42.2 \\
\hline G. paucinervis & & 157,702 & 85,989 & 17,737 & 26,988 & $128(111)$ & $83(77)$ & $8(4)$ & $37(30)$ & 36.2 & 33.6 & 30.3 & 42.2 \\
\hline G. pedunculata & & 157,688 & 85,998 & 17,656 & 27,017 & $128(111)$ & $83(77)$ & $8(4)$ & $37(30)$ & 36.2 & 33.6 & 30.2 & 42.2 \\
\hline
\end{tabular}

*Parentheses indicate the number of unique genes 
Table 2. List of annotated genes in plastomes of Mesta and Manggis.

\begin{tabular}{|c|c|c|}
\hline Function & Group & Gene name \\
\hline \multirow[t]{5}{*}{$\begin{array}{l}\text { Protein synthesis and } \\
\text { DNA-replication }\end{array}$} & Transfer RNA & $\begin{array}{l}\text { trnA-UGC (2X), trnC-GCA, trnD-GUC, trnE-UUC, trnF-GAA, trnfM- } \\
C A U, \text { trnG-GCC, trnH-GUG, trnk-UUU, trnI-GAU (2X), trnL-CAA } \\
(2 \mathrm{X}), \text { trnL-UAA, trnL-UAG, trnM-CAU, trnI-CAU (2X) trnN-GUU (2X), } \\
\text { trnP-UGG, trnQ-UUG, trnR-ACG (2X), trnR-UCU, trnS-CGA, trnS- } \\
G C U, \text { trnS-GGA, trnS-UGA, trnT-GGU, trnT-UGU, trnV-GAC (2X), } \\
\text { trnV-UAC, trnW-CCA, trnY-GUA }\end{array}$ \\
\hline & Ribosomal RNA & $r r n 16(2 \mathrm{X}), r r n 23(2 \mathrm{X}), r r n 4.5(2 \mathrm{X}), \operatorname{rrn} 5(2 \mathrm{X})$ \\
\hline & Ribosomal protein small subunit & $\begin{array}{l}\text { rps } 2, r p s 3, r p s 4, r p s 7(2 \mathrm{X}), r p s 8, r p s 11, r p s 12(2 \mathrm{X}), r p s 14, r p s 15, \text { rps } 16 \text {, } \\
\text { rps } 18, \text { rps } 19\end{array}$ \\
\hline & Ribosomal protein large subunit & rpl2 (2X), rpl14, rpll6, rpl20, rpl22, rpl23 (2X), rpl33, rpl36 \\
\hline & Subunits of RNA polymerase & гроА, гров, гроС1, грос 2 \\
\hline \multirow{6}{*}{ Photosynthesis } & Photosystem I & psaA, psaB, psaC, psaI, psaJ \\
\hline & Photosystem II & $\begin{array}{l}p s b A, p s b B, p s b C, p s b D, p s b E, p s b F, p s b H, p s b I, p s b J, p s b K, p s b L, p s b M, \\
p s b T, p s b Z\end{array}$ \\
\hline & Cytochrome $b_{6} f$ complex & petA, petB, petD, pet $G$, pet $L$, pet $N$ \\
\hline & ATP synthase & atpA, atpB, atpE, atpF, atpH, atpI \\
\hline & NADH-dehydrogenase & $\begin{array}{l}n d h A, n d h B(2 \mathrm{X}), n d h C, n d h D, n d h E, n d h F, n d h G, n d h H, n d h I, n d h J, \\
n d h K\end{array}$ \\
\hline & Large subunit Rubisco & $r b c L$ \\
\hline \multirow[t]{6}{*}{ Miscellaneous group } & Photosystem II protein N & $p s b N$ \\
\hline & Acetyl-CoA carboxylase & $a c c D$ \\
\hline & Cytochrome $\mathrm{c}$ biogenesis & $\operatorname{ccs} A$ \\
\hline & Maturase & matK \\
\hline & ATP-dependent protease & $\operatorname{clpP}$ \\
\hline & Inner membrane protein & cemA \\
\hline $\begin{array}{l}\text { Pseudogene unknown } \\
\text { function }\end{array}$ & $\begin{array}{l}\text { Conserved hypothetical chloroplast } \\
\text { ORF }\end{array}$ & $y c f 1, y c f 2(2 \mathrm{X}), y c f 3, y c f 4$ \\
\hline
\end{tabular}




\section{Plastome feature comparison}

In comparison with the plastomes of other Garcinia species, the plastome sizes of both Mesta and Manggis varieties (156,580 bp and 156,582 bp, respectively) were larger than G. gummigutta $(156,202 \mathrm{bp})$ and G. oblongifolia $(156,577 \mathrm{bp})$, but smaller than G. anomala $(156,774$ bp), G. pedunculata $(157,688 \mathrm{bp})$, G. paucinervis $(157,702 \mathrm{bp})$, and the Thailand variety $(158,179 \mathrm{bp})$.

Gene infA was found in GenBank for G. pedunculata (NC_048983) and G. anomala (MW582313), while gene rpl32 was found for G. pedunculata (NC_048983). However, both genes were not annotated accurately. Multiple sequence alignment of the infA and rpl32 genes (Figure S5) with other species showed that both annotated sequences did not have a conserved region as compared with other species. Hence, these genes were re-annotated and revised for accuracy prior to subsequent comparative analysis.

The number of protein-coding genes (83 CDS) was the same for all the Garcinia species. However, gene trnH-GUG was not found in G. gummi-gutta. Hence, the total number of genes for G. gummi-gutta was 127 compared to 128 genes for other Garcinia species (Table 1). The overall GC content (36.1-36.2\%) and GC content found in LSC (33.5-33.6\%), SSC (30.1-30.3\%), and IR (42.1-42.2\%) were similar among the Garcinia species.

For Garcinia plastomes, there were a total of 18 unique genes (rps16, atpF, rpoCl, ycf3, rps12, clpP, petB, petD, rpl16, rpl2, ndhB, ndhA, trnK-UUU, trnG-UCC, trnL-UAA, trnV$U A C$, trnI-GAU, and trnA-UGC) containing at least one intron with two introns in clpP and rps12 (Table S5), which is similar to those generally found in other plants ${ }^{21}$. Gene $\operatorname{clpP}$ was located in the LSC region. Meanwhile, the 5' exon of the rps12 gene was located in the LSC region while the 3' exon was located in the IR regions, which is commonly observed in plastomes of other species such as, Rhodomyrtus tomentosa, Salvia $\mathrm{spp}^{22,23}$, Ananas comosus var. comosus ${ }^{21}$, and ferns ${ }^{24}$. Among the genes, $\operatorname{trn} K$-UUU had the longest intron length, which is in agreement with previous studies ${ }^{25-27}$.

\section{Codon usage and amino acid frequency}

The total number of codons in 83 protein-coding genes found in the plastomes were different among the Garcinia species ranging from 26,195 in G. pedunculata, 26,216 in Thailand variety, 26,244 in G. paucinervies, 26,249 in G. anomala, 26,257 in both Manggis and Mesta varieties, 26,265 in G. gummi-gutta, to 26,268 in G. oblongifolia (Table S6). There were several common findings in the codon usage analysis of Garcinia plastomes: (1) a total of 20 translated amino acids; (2) the most frequent amino acid was leucine while the least frequent 
was cysteine (Figure S6); (3) there were 30 types of codon out of 64 codons with relative synonymous codon usage (RSCU) values $>1.0$ (ending with either A or U, except for UUG) and 32 types of codons with RSCU $<1.0$ (ending with either $\mathrm{C}$ or G, except for AUA, CUA, and UGA); (4) both AUG and UGG had an RSCU value = 1 (Table S6). Similar findings were also detected in other plants, such as Euphorbiaceae and Rhodomyrtus tomentosa ${ }^{23,28}$,

Generally, the start codon is ATG but there were exceptions for several genes with initiation codons of GTG or ACG due to the RNA editing events during transcription. The first discovery of such an event came from the study of $r p l 2$ gene in the maize plastome when the start codon of this gene changed from ACG to ATG during transcription ${ }^{29}$. Other examples include GTG as an initiation codon of $p s b C$ gene $^{30}$ and ACG for $n d h D$ gene $^{31}$ in the tobacco plastome, start codons ACG and GTG for rpl2 and rps19 genes, respectively in Oryza sativa plastome $^{32}$. Similarly, there were three genes (rpl33, rps19, and $\left.n d h D\right)$ in the plastomes of Garcinia species that did not start with ATG. The start codon was GTG for both rpl33 and rps19 genes in all the Garcinia species, except for rps19 in G. anomala which starts with an ATG. As for $n d h D$, ATG was found in G. anomala while TTG was found in G. pedunculata and ACG for all the other Garcinia species.

\section{Simple Sequence Repeat (SSR) analysis}

A total of 88 SSRs were identified, including 79 mononucleotide repeats, 7 dinucleotide repeats, and two trinucleotide repeats with a total sequence size of 1,065 bp and 1,067 bp for Mesta and Manggis varieties, respectively. The SSRs identified in the plastomes of both Mesta and Manggis were the same except Manggis had additional mononucleotide A (SSR no 3 at Table S7 \& S8) and C (SSR no 25 at Table S7 \& S8), respectively, compared to Mesta. There were 14 SSRs with less than $100 \mathrm{bp}$ in length between two SSRs (compound microsatellite) in both Mesta and Manggis plastomes. The most abundant motif found in both Mesta and Manggis varieties was mononucleotide repeats (89.8\%), in which mononucleotide T (48.9\%) and $\mathrm{A}(38.6 \%)$ constituted the highest portion compared to mononucleotide $\mathrm{C}(1.1 \%)$ and $\mathrm{G}$ $(1.1 \%)$. Among them, only 10 of the mononucleotide repeats were located at the coding regions of $r p o C 2, r p o C 1, r p o B, r p s 19, y c f 2$, and $y c f 1$ genes. All dinucleotide and trinucleotide repeats were located at the non-coding regions, which are common phenomena in flowering plants ${ }^{33}$. All the SSRs in the plastomes of Mesta and Manggis varieties including their respective locations are listed in Table S7 and Table S8, respectively.

The total number of SSR varied among the different Garcinia species (Figure 2). Mesta and Manggis varieties had the lowest number of total SSR (88) compared to G. oblongifolia 
(106), Thailand variety (105), G. gummi-gutta (102), G. anomala (96), G. paucinervis (94), and G. pedunculata (91). Mononucleotide repeats constituted the highest percentage in SSR analysis in this study, which is in agreement with previous studies of plastomes from 164 lower and higher plants ${ }^{33}$. The highest dinucleotide repeat was found in G. oblongifolia (11), followed by Thailand variety (8) and Mesta/Manggis varieties (7) while the other Garcinia species showed 6 dinucleotide repeats. The Thailand variety had 3 trinucleotide repeats, which was the highest among all the Garcinia species. There was only one trinucleotide repeat found in both G. gummi-gutta and G. paucinervis compared to two trinucleotide repeats found in Mesta, Manggis, and G. oblongifolia. Trinucleotide repeat was not found in G. anomala and $G$. pedunculata. The majority of the mononucleotide SSR belonged to the A/T repeats and the same findings were observed in the previous studies ${ }^{21,23,26}$.

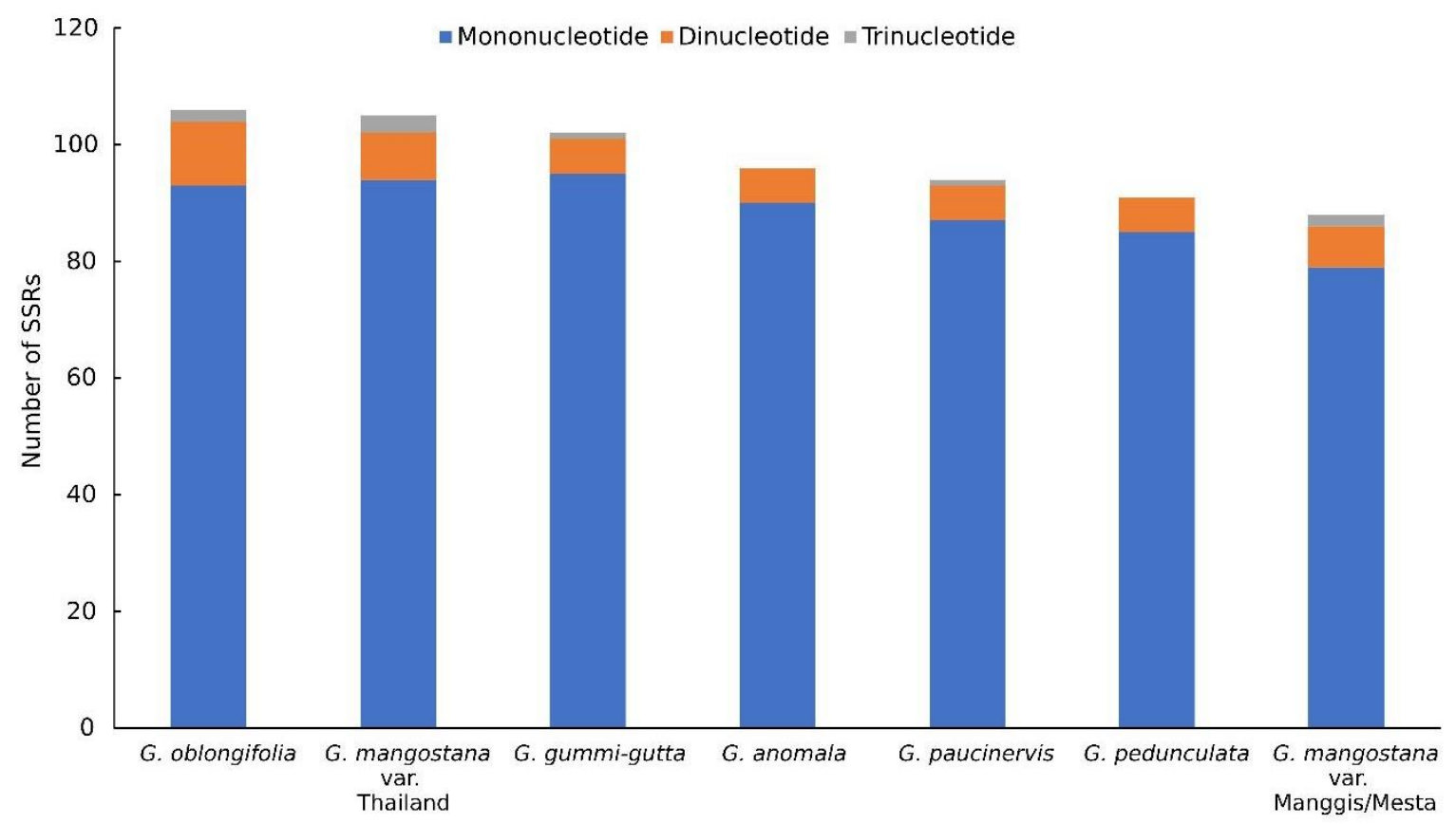

Figure 2. SSR analysis of six Garcinia species plastomes.

\section{Long Repeat Analysis}

By using the default setting of 50 for maximum computed repeats, different types of long repeats were detected in the plastomes of Garcinia species, including forward repeats, reverse repeats, complement repeats, and palindromic repeats (Figure 3). The palindromic repeat was the most common repeat found in Garcinia species followed by the forward repeats, which was also observed in other plants ${ }^{27}$. Mesta and Manggis varieties had the highest number of palindromic repeats of 31, while G. anomala had the lowest number of palindromic repeats of 
25. The reverse repeat was found in all Garcinia species, except G. gummi-gutta which had the highest number of forward repeats (21). G. paucinervis had the highest number of reverse repeats (5), followed by three reverse repeats found in the Thailand variety and G. anomala while the other Garcinia species only had one reverse repeat. In addition, complement repeat was only found in G. anomala (2), Mesta and Manggis varieties (1), and G. paucinervis (1).

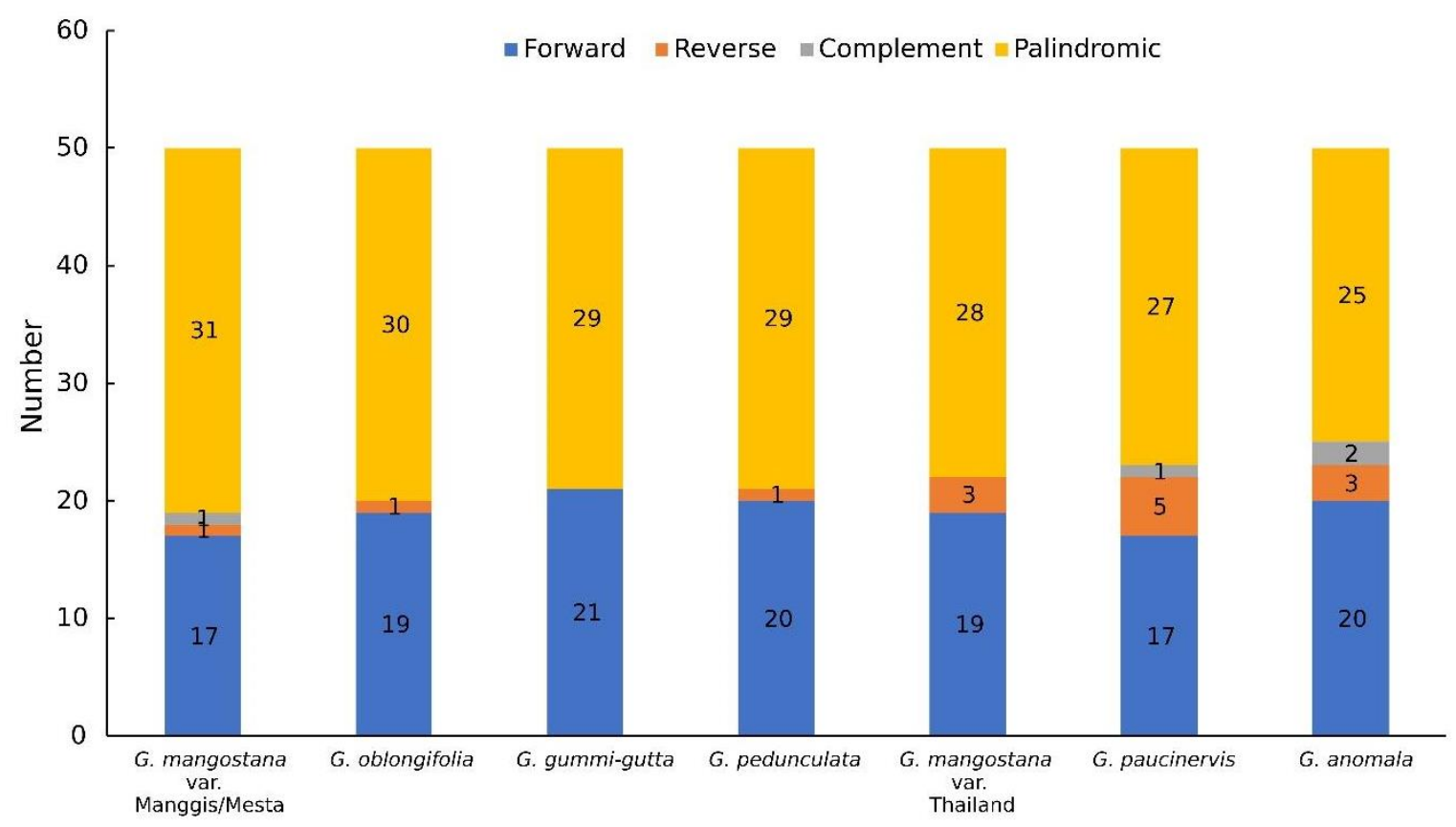

Figure 3. Long repeat analysis of six Garcinia species plastomes.

\section{Contraction and Expansion of the Inverted Repeat Region}

The smallest inverted repeat (IR) was found in G. paucinervis (26,988 bp) while the largest IR was found in G. oblongifolia (27,060 bp) (Figure 4). Genes that can be found at or close to the junctions of IRs were $r p s 19, n d h F, y c f 1$, and $\operatorname{trnH}$. Gene $r p s 19$ was located at the LSC/IRb junction site (JS) and the fragment size located at LSC in all Garcinia species was $60 \mathrm{bp}$, except for the Thailand variety which was only $8 \mathrm{bp}$. In addition, the rps19 gene fragment of the Thailand variety located at IRb site was 1 bp longer (220 bp) than the rps 19 gene fragment (219 bp) of the other Garcinia species at the same location. The $n d h F$ gene spanned across the $\mathrm{SSC} / \mathrm{IRb}$ with 1 bp located at IRb region for G. anomala, G. gummi-gutta, Manggis and Mesta varieties, and G. oblongifolia. However, it was 1 bp away from the SSC/IRb junction site of both G. paucinervis and G. pedunculata. Interestingly, Thailand mangosteen was the only one with $n d h F$ gene $4 \mathrm{bp}$ from the SSC/IRb junction. The $y c f 1$ gene fragment $(1,421 \mathrm{bp})$ in the IRa region was the same for all Garcinia species, except for G. pedunculata and G. paucinervis 
(1,419 bp). The size of the $y c f 1$ fragment in the SSC region range from 4,204 bp to 4,245 bp. In addition, it was found that tRNA-trnH was missing at the IRa/LSC junction of G. gummigutta. In comparison with Erythroxylum novogranatense (Plastome size: 163,937 bp; LSC: 91,383 bp; SSC: 18,138 bp; IR: 27,208 bp), a sister group of G. mangostana ${ }^{15}$, plastome size, LSC, SSC, and IR regions of Garcinia species were much shorter (Figure 4 \& Table 1).

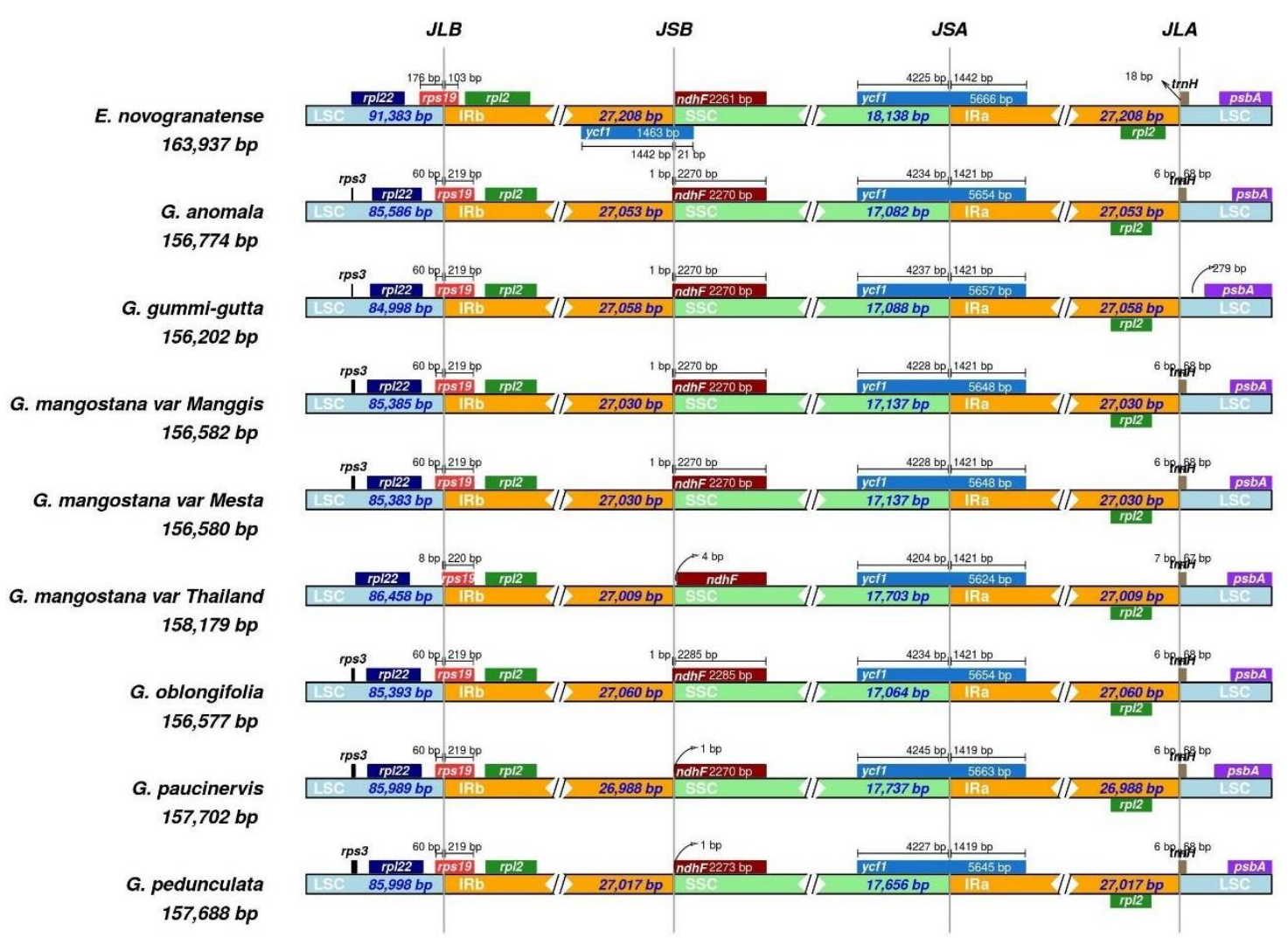

Figure 4. Comparison of genes on the borders of the LSC, SSC, and IR regions among six Garcinia plastomes and Erythroxylum novogranatense. Corresponding plastome size is shown on the left of each track. The intervals show the distance between the start and end coordinates of a particular gene from the junction sites, namely JLB (LSC/IRb), JSB (SSC/IRb), JSA (SSC/IRa), and JLA (LSC/IRa). The sequence length in each region is annotated for genes spanning the junction sites.

\section{Comparative Plastome Analysis}

Plastomes comparison using Mesta as a reference was performed using mVista online alignment tool (Figure 5). The comparison among Garcinia species showed that (1) IR regions were more conserved compared with LSC and SSC regions, (2) coding regions were more conserved than intergenic regions. This result agreed with previous reports in Plantaginaceae, Rosaceae, and Sapindaceae families ${ }^{25,34,35}$. For LSC, highly divergent intergenic regions 
bioRxiv preprint doi: https://doi org/10.1101/2022 02 22.481552; this version posted February 25, 2022. The copyright holder for this preprint (which was not certified by peer review) is the author/funder, who has granted bioRxiv a license to display the preprint in perpetuity. It is made available under aCC-BY-NC-ND 4.0 International license.

include trnH-psbA, trnQ-psbK, trnG-trnR, atpF-atpH, atpH-atpI, trnT-psbD, ndhC-trnV, rbcL$a c c D, p s b B-p s b T$, and intergenic region within the $r p l 16$ gene. As for SSC, the highly divergent regions include $n d h F$-trn $L$ and intergenic region within the $n d h \mathrm{~A}$ gene. Divergent regions were also found in the coding regions such as matK, rpoC2, rpoC1, rpoB, rbcL, accD, ycf4, cernA, petA, petD, rpoA, $n d h F, c c s A, y c f 1$, and ycf2 (Figure 5). In comparison with Erythroxylum novogranatense, plastome sequences of Garcinia species were conserved within the Clusiaceae family.

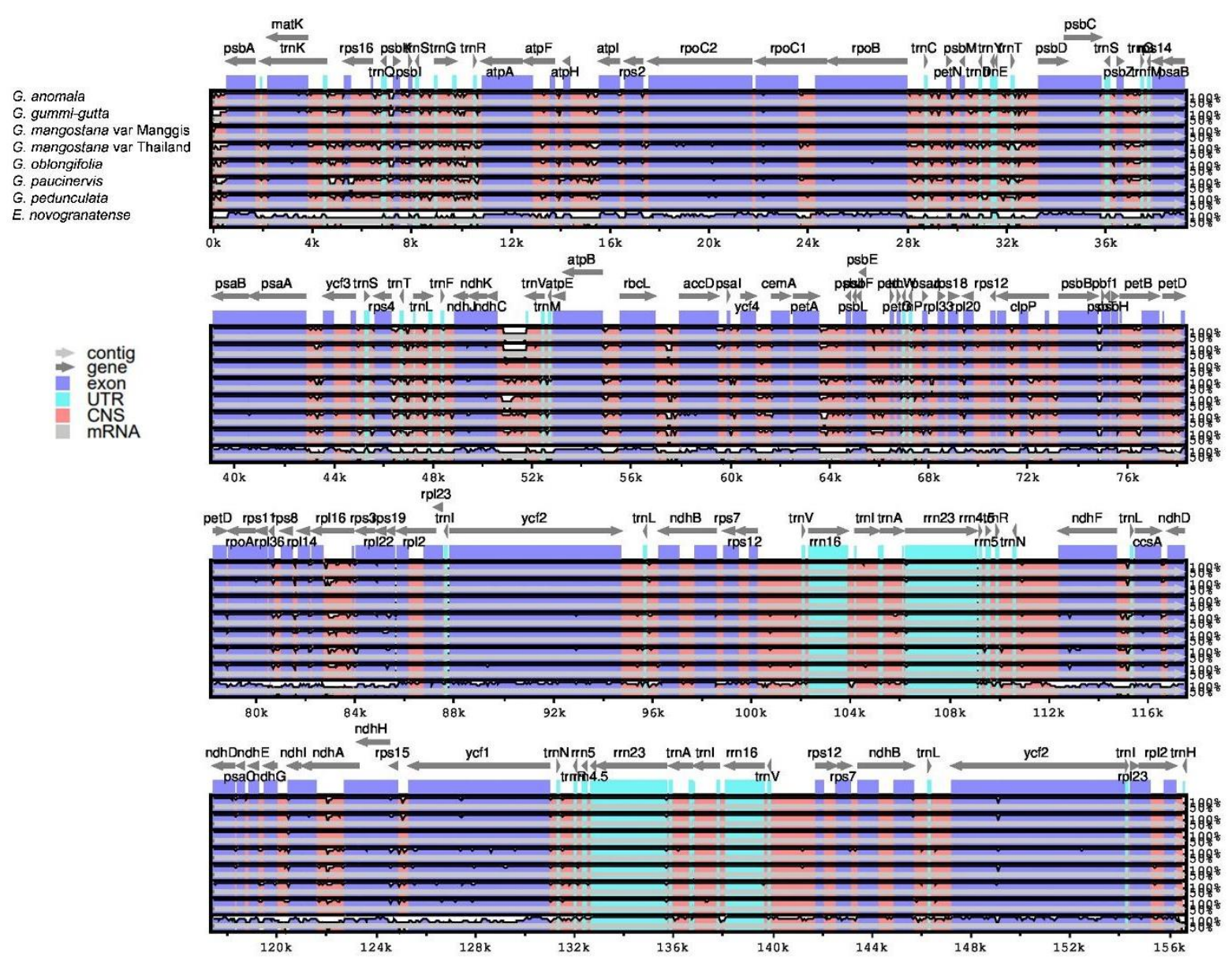

Figure 5. Alignment visualization of Garcinia species using Mesta as a reference by using mVista alignment program. CNS: Conserved Non-Coding Sequences; UTR: Untranslated Region. The gray arrows above the alignment indicate the direction of the gene translation. The identity percentage (50-100\%) was indicated at the right-side of the mVista plot. 


\section{Phylogenomic Analysis}

A total of 74 protein-coding genes (Table S9) were used for phylogenomic analysis. Phylogenomic analysis showed that both Manggis and Mesta varieties were grouped together as the CDS sequences were $100 \%$ identical despite some base differences in non-coding regions. Both were grouped under the clade of Garcinia species in Malpighiales order among the three groups of Garcinia species (Figure 6). G. anomala and G. gummi-gutta were closely related and formed one group with the Mesta/Manggis varieties and G. oblongifolia. The Thailand variety and G. pedunculata formed another group, while G. paucinervis formed the third group in the Clusiaceae family.

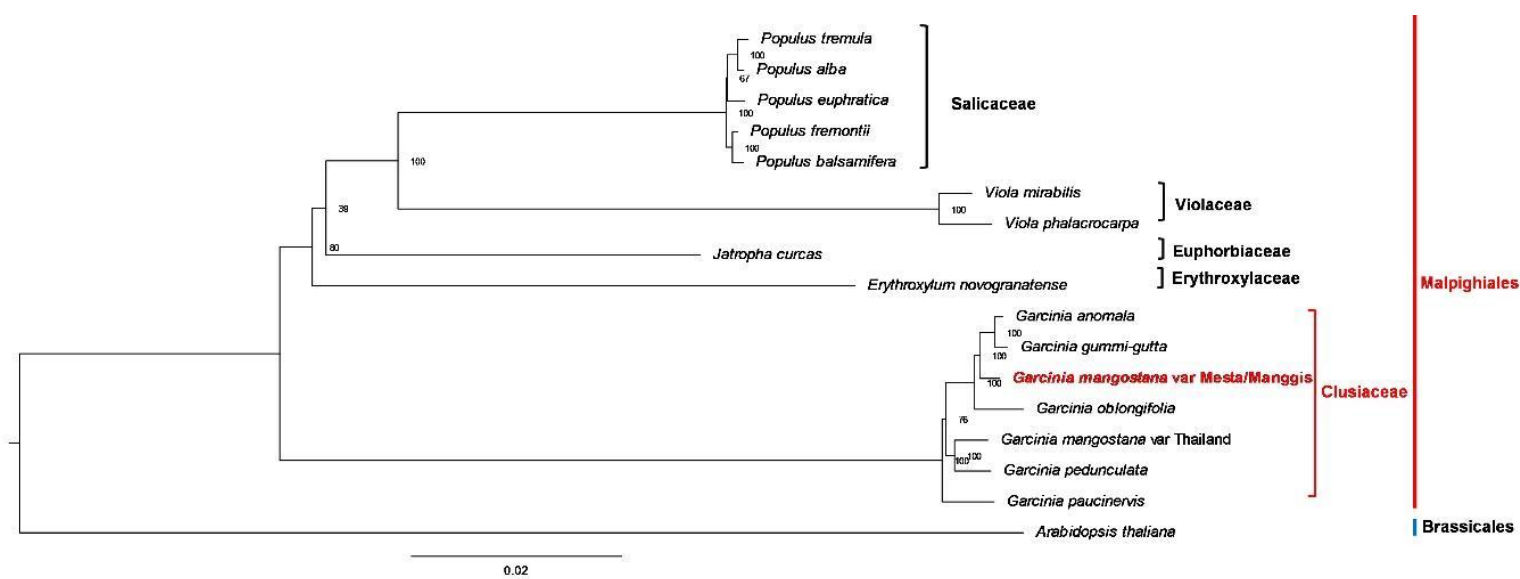

Figure 6. Phylogenetic tree (maximum likelihood) construction of 16 species (three varieties from G. mangostana) based on 74 protein-coding genes. The red outer line indicates order name while the inner line indicates the family name.

\section{Discussion}

Plant DNA is rich in plastome $(\sim 5-20 \%)$ and hence, enrichment strategy is not required for sequencing ${ }^{14}$. In this study, a complete mangosteen plastome of Mesta variety (156,580 bp) was successfully obtained from PacBio long reads. Here, the use of long reads for the assembly of the plastid genomes was ideal to obtain longer contigs and to resolve repetitive regions ${ }^{26,36,37}$. In addition, Illumina sequencing data were used to correct the random errors within PacBio reads ${ }^{38}$. Furthermore, the polished Mesta plastome allowed for the reference-guided assembly of the plastome from Manggis which had only Illumina short reads.

Both the Mesta and Manggis plastomes were nearly identical (Fig. 1), consisting of a typical conserved quadripartite plastome structure found in most of the land plants ${ }^{14,39}$. Generally, the number of genes encoded in a plastome ranges from 110 to 130 genes $^{35}$. Both 
Malaysian mangosteen plastomes fall within the range with 128 genes (111 unique genes), consistent with all other Garcinia species found in GenBank, except for G. gummi-gutta which lost one trnH gene (Table 1). Typically, plastomes have 30-31 tRNAs ${ }^{40,41}$ and the loss of tRNA genes is not uncommon. For instance, two hemiparasitic Taxillus species lost 7 tRNAs, including tRNA-trn $H^{42}$. Sometimes, missing tRNAs might be replaced by other types of anticodons, such as Neochloris aquatica (NC_029670.1), Bracteacoccus giganteas (NC_028586.1), Tetradesmus obliquus (NC_008101.1), Floydiella terrestris (NC_014346.1), Schizomeris leibleinii (NC_015645.1), and Oedogonium cardiacum (NC_011031.1) ${ }^{43}$.

The plastome size, structure, and gene content are highly conserved among Garcinia species. There were 18 genes (12 protein-coding genes and 6 tRNAs) containing intron(s) in the plastomes of Garcinia species. Although introns are not protein-coding, they play an important role in gene expression by regulating the rate of transcription, nuclear export, and stability of transcripts ${ }^{44,45}$. The loss of introns such as $r p l 2$ and $r p s 16$ has been reported in the plant plastomes ${ }^{46-48}$ but, we did not find any evidence of this in the plastomes of Garcinia species.

We detected two mis-annotations of genes (infA and rpl32) in G. pedunculata ${ }^{19}$ and one mis-annotation of infA in G. anomala ${ }^{49}$. The infA is usually located between rpl36 and rps 8 , whereas $r p l 32$ is usually located between $n d h F$ and $t r n L-U A G^{50}$. Instead, the annotated infA was located within rpoCl gene (G. anomala: MW58231349; G. pedunculata: NC048983 ${ }^{51}$ ) while, rpl32 of G. pedunculata was located between $r p o B$ and $\operatorname{trn} C$-GCA. Hence, both genes were actually not found in the Garcinia plastomes, in agreement with a previous report that both infA and rpl32 genes were lost in G. mangostana $^{52}$. Plastid gene transfers to the nuclear genome (e.g., accD, infA, rpl22, and rpl32) have been documented in several plants ${ }^{50,53,54}$. The abundance of infA and rpl32 transcripts in the seed transcriptome ${ }^{4}$ suggests the same scenario for G. mangostana.

Genetic variations in G. mangostana cultivars have been shown by randomly amplified DNA fingerprinting (RAF) and inter simple sequence repeat (ISSR) molecular markers ${ }^{55-57}$. Plastomes also contain SSR and long repeats ${ }^{58,59}$. SSR, which is a stretch of 1-6 bp small repeats, is found extensively in different regions of plastome such as the intergenic regions, intron regions, and protein-coding regions ${ }^{23}$. In contrast, the long repeats found in the plastomes mostly fall within the intergenic region although, some of them were present in protein-coding genes ${ }^{60}$. Repetitive regions might lead to species variation as they have a higher tendency of recombination, translocation, and insertion/deletion ${ }^{61}$. In this study, SSR and long repeat analyses of plastomes showed variations among Garcinia species and varieties of $G$. 
mangostana. This supports that both molecular markers are useful for species identification and taxonomic studies ${ }^{62-64}$.

One of the main factors that contribute to the plastome size differences is the inverted repeat (IR) expansion and contraction ${ }^{65,66}$. For instance, nine genes were transferred from the SSC to the IR region in Plantago ovata resulting in an extremely long IR $(37.4 \mathrm{~kb})^{25}$ as compared to IR found in the other plastomes which normally range between $25 \mathrm{~kb}$ and $30 \mathrm{~kb}^{40}$. In contrast, the loss of IR had been reported in the plastomes of 25 durian varieties recently ${ }^{37}$.

The phylogenomic analysis showed identical protein-coding genes between Mesta and Manggis varieties, which implies the same maternal lineage for both varieties from Malaysia compared to the Thailand variety (Figure 6). This result is congruent with the analysis using the whole plastome sequences of 16 species (Figure S7). The Malaysian (Mesta/Manggis) and Thailand mangosteen varieties did not cluster together in the phylogenomic analysis contrary to the initial hypothesis of this study, which assumed a close phylogenomic relationship of the same species. Analysis of polymorphic sites of the 74 CDS used for phylogenomic tree construction showed a total of 559 variable sites, accounting for $0.85 \%$ differences between Manggis/Mesta and Thailand varieties (Table S10). This was inconsistent with the clustering of different G. mangostana varieties, including the Thailand varieties in a previous phylogenetic study based on the nuclear ITS gene ${ }^{10}$.

To further investigate this discrepancy, we obtained the consensus ITS gene sequences of both Mesta (accession number: OK576276) and Manggis (accession number: OK576274) varieties by mapping the respective Illumina filtered reads against the published ITS gene sequence (accession number: AF367215). We reconstructed a phylogenetic tree ${ }^{10}$ based on the ITS gene sequences of other Garcinia species found in GenBank, including G. celebica, G. gummi-gutta, G. hombroniana, G. oblongifolia, G. paucinervis, and G. pedunculata (Table S11). The ITS phylogenetic tree (Figure S8) showed that all the G. mangostana varieties were grouped with $G$. malaccensis congruent with the results of the previous study ${ }^{10}$. Meanwhile, Mesta and Manggis were distantly related to G. gummi-gutta, G. oblongifolia, G. paucinervis, and G. pedunculata. Furthermore, Mesta, Masta, and G. malaccensis MY4 were clustered together, away from the Manggis variety. This indicates genetic differences between the two varieties despite near-identical plastomes and supports that both varieties might be originated from G. malaccensis.

We found that both Manggis and Mesta varieties showed heterozygosity at certain positions of ITS gene (Manggis: position 200; Mesta: position 444, 477, and 527) based on Illumina short reads results, respectively (Figure S9 \& S10). Out of ten G. mangostana reported 
in the previous study ${ }^{10}$, only one sample (G. mangostana TH3) from Thailand showed heterozygosity. Hence, G. mangostana may not have been derived from the hybridization of G. hombroniana and G. malaccensis ${ }^{9}$. Meanwhile, near-identical Mesta and Manggis plastomes (Figure $1 \& 6$ ) indicate the same maternal lineage. This illustrates the different evolutionary inferences from the nuclear genome and plastome analysis as plastids are inherited maternally compared to recombination events in nuclear genomes during reproduction $^{12}$.

As hybridization is a common practice in plant breeding to produce hybrids with desirable traits ${ }^{67}$, the genetic variations and heterozygosity observed in this study could be due to the different germplasms. Different germplasms may hybridize via selective breeding and could have produced different varieties of G. mangostana in Malaysia and Thailand ${ }^{10}$. However, this remains highly speculative and requires further investigations of mangosteen from different biogeographical origins as well as plastomes of $G$. celebica (syn. $G$. hombroniana), G. malaccensis, G. penangiana, and G. opaca to ascertain their maternal lineages.

\section{Conclusion}

The complete plastomes of both Mesta and Manggis varieties of G. mangostana from Malaysia were successfully assembled and analyzed. PacBio long-read sequencing data helped to resolve the repetitive sequences in Mesta. Subsequently, this allowed reference-guided genome assembly of the Manggis plastome. Notably, the Manggis plastome was almost identical with the Mesta plastome compared to the plastome of Thailand variety. Comparative analysis showed that the gene structure, gene content, gene order, and gene orientation of Garcinia plastomes were largely conserved, except for one missing trnH-GUG gene in G. gummi-gutta. Phylogenomic analysis indicated that the Mesta and Manggis varieties were closer to $G$. anomala, G. gummi-gutta, and G. oblongifolia, while the Thailand variety clustered with $G$. pedunculata. Phylogenetic analysis based on the nuclear ITS sequences delineated the Mesta and Manggis varieties based on differences in their nuclear genomes. This study suggests different origins of the Mesta/Manggis and Thailand varieties. SSR and long repeats of plastomes identified in this study will provide useful biomarkers for species/variety identification and future lineage study of Garcinia genus. 


\section{Materials and methods}

\section{Mesta plastome de novo genome assembly}

Genome sequences of Mesta variety were obtained from the NCBI SRA database with the accession numbers SRX2718652 to SRX2718659 for PacBio long-read data $(9.5 \mathrm{~Gb})^{17}$ and SRX270978 for Illumina short reads $(50.2 \mathrm{~Gb})^{18}$. CANU v2.0 ${ }^{68}$ was used to perform PacBio raw data correction, trimming, and assembly using default parameters with minor modifications (useGrid=false, genomeSize $=6 \mathrm{~g}$, batMemory=252, batThreads=32, minInputCoverage $=0.15$, stopOnLowCoverage $=0$ ). The draft genome assembly was polished with Illumina data using Pilon v1.23 ${ }^{68}$. Candidate plastome contigs were identified by using BLAT v36.0 alignment tool with the previously reported G. mangostana (NC_036341.1) as the query. Identified contig was manually curated based on the read coverage to obtain the final plastome of Mesta for subsequent analysis.

\section{Manggis plastome assembly}

Genome sequences of Manggis variety were obtained from the NCBI SRA database with the accession number SRX1426419 for Illumina reads $(51.1 \mathrm{~Gb})^{16}$. Different methods were used for Manggis variety plastome assembly: (1) reference-guided assembly using GetOrganelle v1.7.5 ${ }^{69}$, (2) de novo assembly using GetOrganelle v1.7.5 ${ }^{69}$, and (3) de novo assembly using Platanus v1.2.4 $4^{70}$ (Figure S11). To select the reference for reference-guided genome assembly, Manggis clean reads were aligned against the complete plastomes of Mesta and Thailand ${ }^{15}$ varieties using bwa-mem v0.7.17 $7^{71}$ and samtools $\mathrm{v} 1.1^{72}$. Next, the mapping coverage was visualized using weeSAM v1.6. The reference with higher percentage coverage was chosen as the final reference for subsequent analysis. Manual curation was performed on the referenceguided assembled Manggis plastome to obtain the final Manggis plastome (Figure S12 \& Table S12).

\section{Plastome annotation}

Plastome annotation was performed online using GeSeq (https://chlorobox.mpimpgolm.mpg.de/geseq.html) ${ }^{73}$. Four Garcinia species [Garcinia gummi-gutta (NC_047250); Garcinia mangostana (NC_036341); Garcinia oblongifolia (NC_050384); and Garcinia pedunculata (NC_048983)] were used as BLAST-like Alignment Tool (BLAT) references. Respective gene annotations were corrected manually. Lastly, the plastome map was generated using Organellar Genome DRAW (OGDRAW v1.3.1) program with default parameters ${ }^{74}$. The 
annotated plastomes of both Mesta and Manggis varieties were submitted to NCBI with accession numbers MZ823408 and OK572535, respectively.

\section{Open Reading Frame (ORF) coordinate adjustment}

The length of each gene found in Garcinia species was compared. Gene alignment was performed to visualize the differences when dissimilarity in gene length was detected by different annotation software. Next, manual coordinate adjustment was performed to standardize the 5'end and the splicing site of these genes (Figure S13 \& Table S13). The adjusted OFR coordinates (Supplementary Data) were used for subsequent analysis.

\section{Identification of Simple-Sequence Repeats (SSRs)}

MISA-web microsatellite identification tool (https://webblast.ipk-gatersleben.de/misa/) ${ }^{75}$ was used to identify SSRs with the following default parameters: the minimum number of repeats for SSR motif of mono-, di-, tri-, tetra-, penta-, hexa- was set to 10, 6, 5, 5, 5, and 5, respectively; the maximum length of sequence between two distinct SSRs was $100 \mathrm{bp}$.

\section{Long Repeat Analysis}

Web-based REPuter (https://bibiserv.cebitec.uni-bielefeld.de/reputer/) ${ }^{76}$ was used to identify forward, reverse, complement, and palindromic repeat sequences using the default setting of 50 for maximum computed repeats; hamming distance was set to 3, and minimal repeat size was set to $30 \mathrm{bp}^{76}$.

\section{Codon Usage Analysis}

Codon usage and relative synonymous codon usage (RSCU) value of all the annotated proteincoding genes presented in the plastomes of Garcinia species were analyzed using the MEGA $\mathrm{X}$ software v10.2.177. The RSCU with value $>1.00$ refers to codon that is frequently used, whereas RSCU with value $<1.00$ refers to codon that is less frequently used. There is no codon usage bias when the RSCU value $=1.00^{78}$.

\section{Plastomes Sequence Alignment and Comparative Analysis}

Plastomes alignment and visualization were performed using the online comparison tool mVista in LAGAN mode ${ }^{79,80}$. Mesta was used as a reference for alignment. The inverted repeat (IR) regions and the junction sites of the large single-copy (LSC) and small single-copy (SSC) regions of all the Garcinia species were compared using IRscope online webtool ${ }^{81}$ for the 
bioRxiv preprint doi: https://doi.org/10.1101/2022.02.22.481552; this version posted February 25, 2022. The copyright holder for this preprint (which was not certified by peer review) is the author/funder, who has granted bioRxiv a license to display the preprint in perpetuity. It is made available under aCC-BY-NC-ND 4.0 International license.

visualization of the expansion or contraction events. For both analyses, Erythroxylum novogranatense, from Erythroxylaceae family of the same order Malpighiales was included.

\section{Phylogenomic Analysis}

For phylogenomic analysis, sixteen species were used: six Garcinia species (including $G$. mangostana var. Manggis, Mesta, and Thailand), five Populus species, two Viola species, Erythroxylum novogranatense, and Jatropha curcas from the order Malpighiales and Arabidopsis thaliana from the order Brassicales. A total of 74 protein-coding genes (Table S9) that were commonly found in the plastomes of these 16 species (three varieties from $G$. mangsotana) were downloaded from NCBI Organelle Genome database. These protein-coding genes were concatenated before aligned using MAFFT version 7 online tool (https://mafft.cbrc.jp/alignment/server/) ${ }^{82}$. Next, ModelTest-NG v0.1.6 $6^{83}$ was used to select the DNA Evolutionary Models. The best model selected was GTR $+\mathrm{I}+\mathrm{G} 4$ and it was used in the subsequent maximum likelihood (ML) analysis using RAxML-NG v1.0.2 tool $^{84}$.

\section{Data Availability Statement}

The complete plastome sequences and ITS gene sequences of Garcinia mangostana var. Mesta and var. Manggis have been submitted to GenBank. The accession numbers for plastome sequences are MZ823408 and OK572535 for Garcinia mangostana var. Mesta and var. Manggis, respectively. Meanwhile, the ITS gene sequences of Garcinia mangostana var. Mesta and var. Manggis are OK576276 and OK576274, respectively.

\section{References}

1 Aizat, W. M., Jamil, I. N., Ahmad-Hashim, F. H. \& Noor, N. M. Recent updates on metabolite composition and medicinal benefits of mangosteen plant. PeerJ 7, e6324, doi:10.7717/peerj.6324 (2019).

2 Mamat, S. F., Azizan, K. A., Baharum, S. N., Noor, N. M. \& Aizat, W. M. GC-MS and LCMS analyses reveal the distribution of primary and secondary metabolites in mangosteen (Garcinia mangostana Linn.) fruit during ripening. Scientia Horticulturae 262, 109004 (2020).

3 Sprecher, A. Étude sur la semence et la germination du Garcinia mangostana L. (Librairie Générale de l'Enseignement, 1919).

4 Goh, H. H., Abu Bakar, S., Kamal Azlan, N. D., Zainal, Z. \& Mohd Noor, N. Transcriptional reprogramming during Garcinia-type recalcitrant seed germination of Garcinia mangostana. Scientia Horticulturae 257, doi:10.1016/j.scienta.2019.108727 (2019).

5 Chinawat, Y. \& Subhadrabhanu, S. Phylogenetic relationship of Mangosteen and several wild relatives revealed by ITS Sequence data. Journal of the American Society for Horticultural Science 129, 368-373 (2004).

6 Nazre, M., Clyde, M. \& Latiff, A. Phylogenetic relationships of locally cultivated Garcinia species with some wild relatives. Malaysian Applied Biology 36, 31 (2007).

7 Sweeney, P. W. Phylogeny and floral diversity in the genus Garcinia (Clusiaceae) and relatives. International Journal of Plant Sciences 169, 1288-1303 (2008). 
bioRxiv preprint doi: https://doi.org/10.1101/2022.02.22.481552; this version posted February 25, 2022. The copyright holder for this preprint (which was not certified by peer review) is the author/funder, who has granted bioRxiv a license to display the preprint in perpetuity. It is made available under aCC-BY-NC-ND 4.0 International license.

Saleh, M. Taxonomic revision and molecular studies of Garcinia section Garcinia (Guttiferae), University of Edinburgh, (2006).

Richards, A. Studies in Garcinia, dioecious tropical forest trees: the origin of the mangosteen (G. mangostana L.). Botanical Journal of the Linnean Society 103, 301-308 (1990).

Nazre, M. New evidence on the origin of mangosteen (Garcinia mangostana L.) based on morphology and ITS sequence. Genetic Resources and Crop Evolution 61, 1147-1158 (2014). $\mathrm{Bi}$, Y. et al. Chloroplast genomic resources for phylogeny and DNA barcoding: a case study on Fritillaria. Scientific Reports 8, 1184, doi:10.1038/s41598-018-19591-9 (2018).

12 Raspé, O. Inheritance of the chloroplast genome in Sorbus aucuparia L. (Rosaceae). Journal of Heredity 92, 507-509, doi:10.1093/jhered/92.6.507 (2001).

3 Cheon, K.-S., Kim, K.-A., Kwak, M., Lee, B. \& Yoo, K.-O. The complete chloroplast genome sequences of four Viola species (Violaceae) and comparative analyses with its congeneric species. PLoS One 14, e0214162 (2019).

Tonti-Filippini, J., Nevill, P. G., Dixon, K. \& Small, I. What can we do with 1000 plastid genomes?, (Wiley Online Library, 2017).

5 Jo, S. et al. The complete plastome of tropical fruit Garcinia mangostana (Clusiaceae). Mitochondrial DNA Part B 2, 722-724, doi:10.1080/23802359.2017.1390406 (2017).

Abu Bakar, S., Sampathrajan, S., Loke, K. K., Goh, H. H. \& Mohd Noor, N. DNA-seq analysis of Garcinia mangostana. Genomics Data 7, 62-63, doi:10.1016/j.gdata.2015.11.018 (2016).

1 Midin, M. R. et al. SMRT sequencing data for Garcinia mangostana L. variety Mesta. Genomics Data 12, 134-135, doi:10.1016/j.gdata.2017.04.003 (2017).

1 Abu Bakar, S., Kumar, S., Loke, K. K., Goh, H. H. \& Mohd Noor, N. DNA shotgun sequencing analysis of Garcinia mangostana L. variety Mesta. Genomics Data 12, 118-119, doi:10.1016/j.gdata.2017.05.001 (2017).

9 Wang, Y., Zhao, B., Lu, Z., Shi, Y. \& Li, J. The complete chloroplast genome provides insight into the polymorphism and adaptive evolution of Garcinia paucinervis. Biotechnology \& Biotechnological Equipment 35, 377-391 (2021).

Krumsiek, J., Arnold, R. \& Rattei, T. Gepard: a rapid and sensitive tool for creating dotplots on genome scale. Bioinformatics 23, 1026-1028 (2007).

Redwan, R., Saidin, A. \& Kumar, S. Complete chloroplast genome sequence of MD-2 pineapple and its comparative analysis among nine other plants from the subclass Commelinidae. BMC Plant Biology 15, 1-20 (2015).

2 Gao, C. et al. Characterization of chloroplast genomes from two Salvia medicinal plants and gene transfer among their mitochondrial and chloroplast genomes. Frontiers in Genetics 11, doi:10.3389/fgene.2020.574962 (2020).

Huang, Y. et al. Comprehensive analysis of Rhodomyrtus tomentosa chloroplast genome. Plants 8, 89 (2019).

4 Liu, S., Wang, Z., Wang, H., Su, Y. \& Wang, T. Patterns and rates of plastid rps12 gene evolution inferred in a phylogenetic context using plastomic data of ferns. Scientific Reports 10, 9394, doi:10.1038/s41598-020-66219-y (2020).

Asaf, S. et al. Expanded inverted repeat region with large scale inversion in the first complete plastid genome sequence of Plantago ovata. Scientific reports 10, 1-16 (2020).

6 Chen, X., Li, Q., Li, Y., Qian, J. \& Han, J. Chloroplast genome of Aconitum barbatum var. puberulum (Ranunculaceae) derived from CCS reads using the PacBio RS platform. Frontiers in Plant Science 6, 42 (2015).

7 Li, D.-M., Zhao, C.-Y. \& Liu, X.-F. Complete chloroplast genome sequences of Kaempferia galanga and Kaempferia elegans: molecular structures and comparative analysis. Molecules 24, 474 (2019).

Wang, Z. et al. Comparative analysis of codon usage patterns in chloroplast genomes of six Euphorbiaceae species. PeerJ 8, e8251 (2020).

Hoch, B., Maier, R. M., Appel, K., Igloi, G. L. \& Kössel, H. Editing of a chloroplast mRNA by creation of an initiation codon. Nature 353, 178-180, doi:10.1038/353178a0 (1991).

Kuroda, H. et al. Translation of psbC mRNAs starts from the downstream GUG, not the upstream AUG, and requires the extended Shine-Dalgarno sequence in tobacco chloroplasts. Plant and Cell Physiology 48, 1374-1378, doi:10.1093/pcp/pcm097 (2007). 
bioRxiv preprint doi: https://doi.org/10.1101/2022.02.22.481552; this version posted February 25, 2022. The copyright holder for this preprint (which was not certified by peer review) is the author/funder, who has granted bioRxiv a license to display the preprint in perpetuity. It is made available under aCC-BY-NC-ND 4.0 International license.

31 Hirose, T. \& Sugiura, M. Both RNA editing and RNA cleavage are required for translation of tobacco chloroplast ndhD mRNA: a possible regulatory mechanism for the expression of a chloroplast operon consisting of functionally unrelated genes. The EMBO journal 16, 68046811 (1997).

32 Po, L. Q. \& Zhong, X. Q. Codon usage in the chloroplast genome of rice (Oryza sativa L ssp japonica). Acta Agronomica Sinica, 12 (2004).

33 George, B., Bhatt, B. S., Awasthi, M., George, B. \& Singh, A. K. Comparative analysis of microsatellites in chloroplast genomes of lower and higher plants. Current Genetics 61, 665677, doi:10.1007/s00294-015-0495-9 (2015).

34 Dong, F., Lin, Z., Lin, J., Ming, R. \& Zhang, W. Chloroplast genome of rambutan and comparative analyses in Sapindaceae. Plants 10, 283 (2021).

35 Xue, S. et al. Comparative analysis of the complete chloroplast genome among Prunus mume, $P$. armeniaca, and P. salicina. Horticulture research 6, 1-13 (2019).

36 Ferrarini, M. et al. An evaluation of the PacBio RS platform for sequencing and de novo assembly of a chloroplast genome. BMC genomics 14, 1-12 (2013).

37 Shearman, J. R. et al. Assembly of the durian chloroplast genome using long PacBio reads. Scientific reports 10, 1-8 (2020).

38 Wu, Z. et al. A precise chloroplast genome of Nelumbo nucifera (Nelumbonaceae) evaluated with Sanger, Illumina MiSeq, and PacBio RS II sequencing platforms: insight into the plastid evolution of basal eudicots. BMC Plant Biology 14, 1-14 (2014).

39 Zhu, A., Guo, W., Gupta, S., Fan, W. \& Mower, J. P. Evolutionary dynamics of the plastid inverted repeat: the effects of expansion, contraction, and loss on substitution rates. New Phytologist 209, 1747-1756 (2016).

40 Wicke, S., Schneeweiss, G. M., Depamphilis, C. W., Müller, K. F. \& Quandt, D. The evolution of the plastid chromosome in land plants: gene content, gene order, gene function. Plant molecular biology 76, 273-297 (2011).

41 Bock, R. in Cell and molecular biology of plastids 29-63 (Springer, 2007).

$42 \mathrm{Li}$, Y. et al. Gene losses and partial deletion of small single-copy regions of the chloroplast genomes of two hemiparasitic Tax i llus species. Scientific reports 7, 1-12 (2017).

43 Qi, F. et al. Structural variation and evolution of chloroplast tRNAs in green algae. PeerJ 9, e11524 (2021).

44 Shaul, O. How introns enhance gene expression. The International Journal of Biochemistry \& Cell Biology 91, 145-155 (2017).

45 Heyn, P., Kalinka, A. T., Tomancak, P. \& Neugebauer, K. M. Introns and gene expression: cellular constraints, transcriptional regulation, and evolutionary consequences. Bioessays 37, 148-154 (2015).

46 Liu, L. et al. Chloroplast genome analyses and genomic resource development for epilithic sister genera Oresitrophe and Mukdenia (Saxifragaceae), using genome skimming data. BMC Genomics 19, 235, doi:10.1186/s12864-018-4633-x (2018).

47 Downie, S. R. et al. Six independent losses of the chloroplast DNA rpl2 intron in dicotyledons: molecular and phylogenetic implications. Evolution 45, 1245-1259 (1991).

48 Haberle, R. C., Fourcade, H. M., Boore, J. L. \& Jansen, R. K. Extensive rearrangements in the chloroplast genome of Trachelium caeruleum are associated with repeats and tRNA genes. Journal of Molecular Evolution 66, 350-361 (2008).

49 Yue, B. \& Shi, J. The complete chloroplast genome sequence of Garcinia anomala (Clusiaceae) from Yunnan Province, China. Mitochondrial DNA Part B 6, 1899-1900 (2021).

50 Alqahtani, A. A. \& Jansen, R. K. The evolutionary fate of rpl32 and rps16 losses in the Euphorbia schimperi (Euphorbiaceae) plastome. Scientific reports 11, 1-12 (2021).

51 Yang, D., Qiu, Q., Xu, L., Xu, Y. \& Wang, Y. The complete chloroplast genome sequence of Garcinia pedunculata. Mitochondrial DNA Part B 5, 220-221, doi:10.1080/23802359.2019.1699470 (2020).

52 Jin, D.-M., Jin, J.-J. \& Yi, T.-S. Plastome structural conservation and evolution in the clusioid clade of Malpighiales. Scientific reports 10, 1-6 (2020). 
bioRxiv preprint doi: https://doi.org/10.1101/2022.02.22.481552; this version posted February 25, 2022. The copyright holder for this preprint (which was not certified by peer review) is the author/funder, who has granted bioRxiv a license to display the preprint in perpetuity. It is made available under aCC-BY-NC-ND 4.0 International license.

53 Millen, R. S. et al. Many parallel losses of infA from chloroplast DNA during angiosperm evolution with multiple independent transfers to the nucleus. The Plant Cell 13, 645-658 (2001).

54 Park, S., Jansen, R. K. \& Park, S. Complete plastome sequence of Thalictrum coreanum (Ranunculaceae) and transfer of the rpl32 gene to the nucleus in the ancestor of the subfamily Thalictroideae. BMC Plant Biology 15, 1-12 (2015).

55 Ramage, C. M., Sando, L., Peace, C. P., Carroll, B. J. \& Drew, R. A. Genetic diversity revealed in the apomictic fruit species Garcinia mangostana L. (mangosteen). Euphytica 136, 1-10 (2004).

56 Sando, L., Peace, C., Ramage, C., Carrol, B. \& Drew, R. in International Symposium on Biotechnology of Tropical and Subtropical Species 692. 143-152.

57 Sobir, S., Poerwanto, R., Santosa, E., Sinaga, S. \& Mansyah, E. Genetic variability in apomictic mangosteen (Garcinia mangostana) and its close relatives (Garcinia spp.) based on ISSR markers. Biodiversitas Journal of Biological Diversity 12 (2011).

58 Zhu, M. et al. Phylogenetic significance of the characteristics of simple sequence repeats at the genus level based on the complete chloroplast genome sequences of Cyatheaceae. Ecology and Evolution 11, 14327-14340, doi:10.1002/ece3.8151 (2021).

59 Alzahrani, D. A., Yaradua, S. S., Albokhari, E. J. \& Abba, A. Complete chloroplast genome sequence of Barleria prionitis, comparative chloroplast genomics and phylogenetic relationships among Acanthoideae. BMC Genomics 21, 393, doi:10.1186/s12864-020-06798-2 (2020).

60 Guo, Y.-Y., Yang, J.-X., Li, H.-K. \& Zhao, H.-S. Chloroplast genomes of two species of Cypripedium: Expanded genome size and proliferation of AT-biased repeat sequences. Frontiers in Plant Science 12, 609729-609729, doi:10.3389/fpls.2021.609729 (2021).

61 Dunn, M. J. \& Anderson, M. Z. To repeat or not to repeat: Repetitive sequences regulate genome stability in Candida albicans. Genes (Basel) 10, 866, doi:10.3390/genes10110866 (2019).

62 Yao, J. et al. Complete chloroplast genome sequencing and phylogenetic analysis of two Dracocephalum plants. BioMed Research International 2020 (2020).

63 Huang, J. et al. Development of chloroplast microsatellite markers and analysis of chloroplast diversity in Chinese jujube (Ziziphus jujuba Mill.) and wild jujube (Ziziphus acidojujuba Mill.). PLoS One 10, e0134519 (2015).

64 Park, H., Kim, C., Lee, Y. M. \& Kim, J. H. Development of chloroplast microsatellite markers for the endangered Maianthemum bicolor (Asparagaceae sl). Applications in Plant Sciences 4, 1600032 (2016).

65 Bock, R. \& Knoop, V. Genomics of chloroplasts and mitochondria. Vol. 35 (Springer Science \& Business Media, 2012).

66 Chen, H. et al. Sequencing and analysis of Strobilanthes cusia (Nees) Kuntze chloroplast genome revealed the rare simultaneous contraction and expansion of the inverted repeat region in angiosperm. Frontiers in plant science 9, 324 (2018).

67 Goulet, B. E., Roda, F. \& Hopkins, R. Hybridization in plants: Old ideas, new techniques. Plant Physiol 173, 65-78, doi:10.1104/pp.16.01340 (2017).

68 Walker, B. J. et al. Pilon: An integrated tool for comprehensive microbial variant detection and genome assembly improvement. PLOS ONE 9, e112963, doi:10.1371/journal.pone.0112963 (2014).

69 Jin, J.-J. et al. GetOrganelle: a fast and versatile toolkit for accurate de novo assembly of organelle genomes. Genome Biology 21, 241, doi:10.1186/s13059-020-02154-5 (2020).

70 Kajitani, R. et al. Efficient de novo assembly of highly heterozygous genomes from wholegenome shotgun short reads. Genome research 24, 1384-1395 (2014).

$71 \mathrm{Li}, \mathrm{H}$. Aligning sequence reads, clone sequences and assembly contigs with BWA-MEM. arXiv, arXiv:1303.3997 (2013).

$72 \mathrm{Li}$, H. et al. The sequence alignment/map format and SAMtools. Bioinformatics 25, 2078-2079 (2009).

73 Tillich, M. et al. GeSeq - versatile and accurate annotation of organelle genomes. Nucleic Acids Res 45, W6-w11, doi:10.1093/nar/gkx391 (2017). 
74 Greiner, S., Lehwark, P. \& Bock, R. OrganellarGenomeDRAW (OGDRAW) version 1.3.1: expanded toolkit for the graphical visualization of organellar genomes. Nucleic Acids Research 47, W59-W64, doi:10.1093/nar/gkz238 (2019).

75 Beier, S., Thiel, T., Münch, T., Scholz, U. \& Mascher, M. MISA-web: a web server for microsatellite prediction. Bioinformatics 33, 2583-2585 (2017).

76 Kurtz, S. et al. REPuter: the manifold applications of repeat analysis on a genomic scale. Nucleic acids research 29, 4633-4642, doi:10.1093/nar/29.22.4633 (2001).

77 Kumar, S., Stecher, G., Li, M., Knyaz, C. \& Tamura, K. MEGA X: molecular evolutionary genetics analysis across computing platforms. Molecular biology and evolution 35, 1547 (2018).

78 Harman, G. E. \& Kubicek, C. P. Trichoderma and gliocladium: basic biology, taxonomy and genetics. Vol. 1 (CRC Press, 2002).

79 Frazer, K. A., Pachter, L., Poliakov, A., Rubin, E. M. \& Dubchak, I. VISTA: computational tools for comparative genomics. Nucleic acids research 32, W273-W279 (2004).

80 Brudno, M. et al. LAGAN and Multi-LAGAN: efficient tools for large-scale multiple alignment of genomic DNA. Genome research 13, 721-731 (2003).

81 Amiryousefi, A., Hyvönen, J. \& Poczai, P. IRscope: an online program to visualize the junction sites of chloroplast genomes. Bioinformatics 34, 3030-3031, doi:10.1093/bioinformatics/bty220 (2018).

82 Katoh, K., Rozewicki, J. \& Yamada, K. D. MAFFT online service: multiple sequence alignment, interactive sequence choice and visualization. Briefings in bioinformatics 20, 11601166 (2019).

83 Darriba, D. et al. ModelTest-NG: A new and scalable tool for the selection of DNA and protein evolutionary models. Molecular Biology and Evolution 37, 291-294, doi:10.1093/molbev/msz189 (2020).

84 Kozlov, A. M., Darriba, D., Flouri, T., Morel, B. \& Stamatakis, A. RAxML-NG: a fast, scalable and user-friendly tool for maximum likelihood phylogenetic inference. Bioinformatics 35, 4453-4455, doi:10.1093/bioinformatics/btz305 (2019).

\section{Acknowledgments}

We would like to acknowledge the support of this research by Universiti Kebangsaan Malaysia (UKM) Research University grant AP-2012-018. The group is currently supported by UKM Research University grant DIP-2020-005 (H-HG) and NIG-JOINT grant 2021 (2A2021) (NY and $\mathrm{H}-\mathrm{HG})$, Japan..

\section{Author Contribution Statement}

C.C.W. and H.H.G. conceived and planned the experiment. C.C.W. wrote the paper and analyzed the data. Y.N. contributed to the data analysis. H.H.G., N.A.N.M., V.K.S., M.A., and Y.N. reviewed and edited the manuscript. All authors read and approved the manuscript.

\section{Additional information}

Supplementary Tables: Figure S1-S13

Supplementary Figures: Table S1-S13

Supplementary Data 


\section{Conflict of Interest}

The authors declare no competing interests.

\section{Legends}

\section{Figures}

Figure 1. The circular plastome of G. mangostana variety Mesta and Manggis. Genes inside the circle are transcribed clockwise while genes outside the circle are transcribed anticlockwise as indicated by the gray arrows.

Figure 2. SSR analysis of six Garcinia species plastomes.

Figure 3. Long repeat analysis of six Garcinia species plastomes.

Figure 4. Comparison of genes on the borders of the LSC, SSC, and IR regions among six Garcinia plastomes and Erythroxylum novogranatense.

Figure 5. Alignment visualization of Garcinia species using Mesta as a reference by using mVista alignment program.

Figure 6. Phylogenetic tree (maximum likelihood) construction of 16 species (three varieties from G. mangostana) based on 74 protein-coding genes.

\section{Tables}

Table 1. Summary statistics of plastomes from different Garcinia species.

Table 2. List of annotated genes in plastomes of Mesta and Manggis. 